\title{
POWER OVER LIFE AND
DEATH Natalie Köhle
}

$\mathrm{H}$

ARBIN. NOVEMBER 2017. Sergio

Canavero and Ren Xiaoping 任晓 平 announced that the world's first human head transplant was 'imminent'. They had just completed an eighteen-hour rehearsal on two human cadavers, and now claimed to be ready for the real deal: the transplant of a human head from a living person with a degenerative disease onto a healthy, but brain-dead, donor body. ${ }^{1}$

Ren - a US-educated Chinese orthopaedic surgeon, was part of the team that performed the first hand transplant in Louisville in 1999. Canavero, an Italian, and former neurosurgeon at the university of Turin, is the more controversial, maverick persona of the team. In addition to many respected scientific publications, he published Immortal: Why CONSCIOUS-
NESS is NOT in the BRAIN, which seeks to prove the existence of an eternal soul on the basis of near death experience, as well as two guides on seducing women. He also drops flippant references to Stalin or the Nazi doctor Josef Mengele.

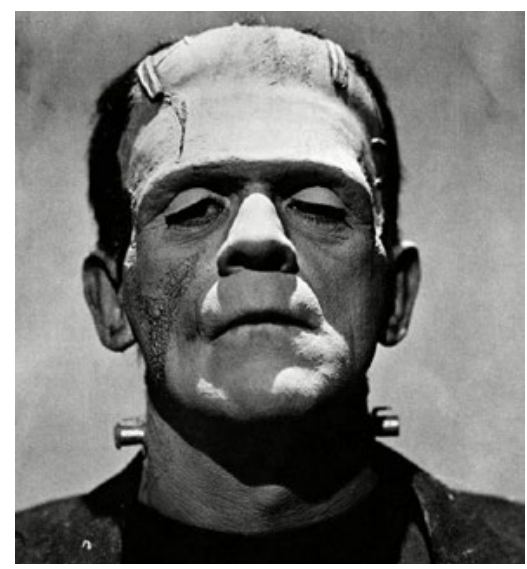

Frankenstein's Monster from The Bride of Frankenstein (1935)

Source: Commons Wikimedia 


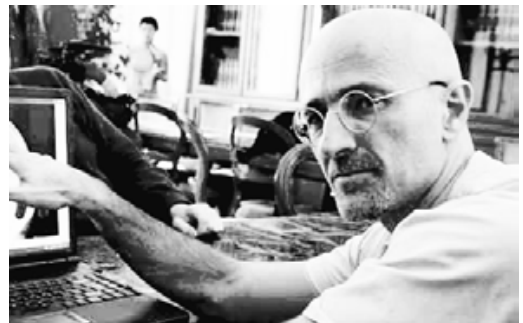

Sergio Canavero

Source: 诗凯 陆, Flickr

Ren and Canavero see the head transplant, formally known as cephalosomatic anastomosis, as the logical next step in the trajectory of transplant surgery. They regard as their intellectual ancestors the Soviet surgeon Vladimir Demikhov, who on a number of occasions experimented with grafting the head and limbs of one dog onto another host dog in the 1950s, and the American Robert White, who performed monkey head transplants in the 1970s - and became the target of massive criticism by animal rightists and ethicists.

The consensus in the scientific community is that such an operation is still light years ahead of current skills and capabilities, and not backed up by sufficient, peer-reviewed research. Its success would hinge on the surgeons' ability to connect the spinal cords of two different bodies, joining millions of nerves that are responsible for mo- tor function and sensation. It would also depend on the unproven capacity of the human brain to adjust to - and gain control over - a new body and a new nervous system without suffering debilitating pain or going mad. ${ }^{2}$

So far, Ren and Canavero have transplanted the heads of numerous lab mice and one monkey, and they have also severed and subsequently mended the spinal cords of several dogs. Amazingly, some of the mice and dogs regained motor functions to some extent. Yet neuroscientists have yet to succeed in mending injured or severed spinal cords within a singular human

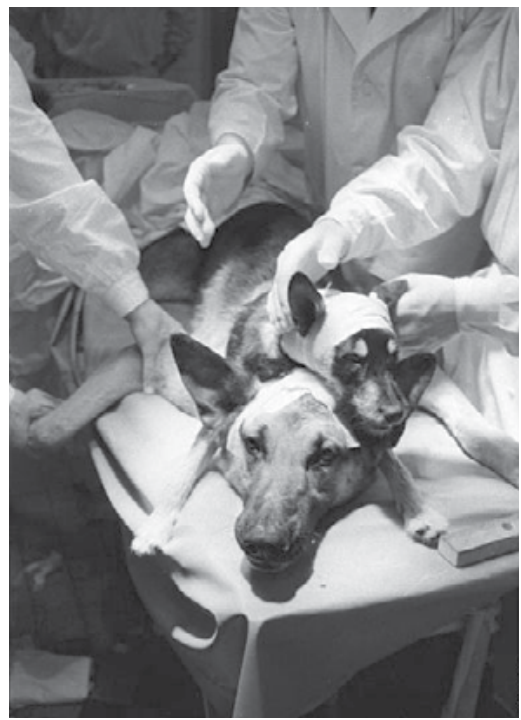

One of Demikhov's two-headed dogs Source: Commons Wikimedia 
body, and Canavero and Ren have not proven that it is possible to preserve the mobility of a primate following a head transplant.

That said, Emeritus Professor of Neurosurgery at UCLA and editor-in-chief of Surgical Neurology International (SNI) James I. Ausman referred to Canavero and Ren's project as a 'quantum leap in Medical Science', and praised them for having done 'a superb job of establishing the foundation for this operation to proceed' in a curious editorial for $S N I .^{3} S N I$ is also the journal that features an entire section on 'Head and Spinal Cord Transplantation', in which most of the research on head transplant surgery, including the report on the recent trial run on two human cadavers, is published - edited by Canavero and Ren!

A recent issue of the American Journal of Bioethics - Neuroscience
(AJOB Neuroscience), devoted entirely to a discussion of the project, was unanimously critical of it. ${ }^{4}$ Arthur Kaplan, head of medical ethics at the New York University medical school, expressed the general consensus of Western bio- and neuro-ethicists when he stated that the proposed head transplant was 'both rotten scientifically and lousy ethically'. ${ }^{5}$ It poses daunting questions pertaining to personal identity including the legal definition of a person.

Ren and Canavero's project hinges on the assumption that a person is defined by his (or her) brain. Research on the enteric nervous system (ENS) and the microbiome has brought this cerebro-centric view of personhood into question. The ENS is the second-largest nervous system in the body - often described as a 'second brain' in the gut. The microbiome is an ecological com-
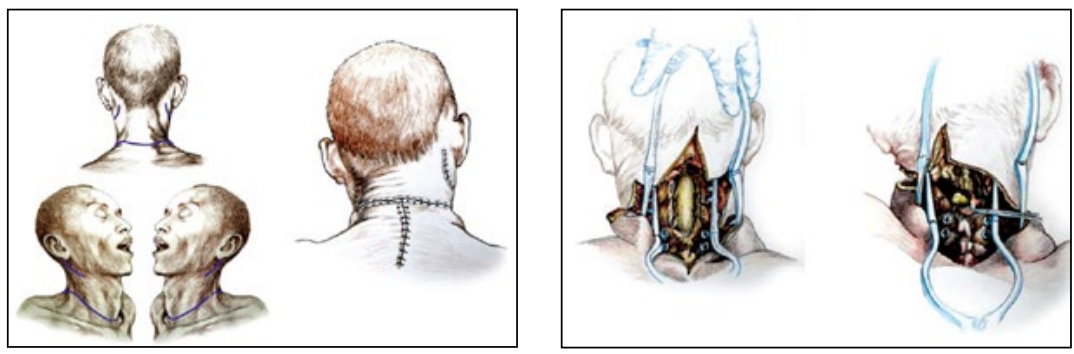

Sketch from Canavero and Ren's Nov 2017 Cadaveric Rehearsal

Source: Ren Xiaoping, Li Ming, Zhao Xin, Liu Zehan, Ren Shuai, Zhang Yafang, Zhang Shide, Sergio Canavero, 'First Cephalosomatic Anastomosis in a Human Model', Surgical Neurology International, 17 November 2017, 8:276 
munity of microorganisms including bacteria, fungi, and viruses that live inside the human organism, with a composition that is unique to each person. Recent research suggests that the ENS and the microbiome may be significantly responsible for an individual's personality traits. ${ }^{6}$ Hence the hybrid to emerge from the head transplant could end up with competing personalities. They will also inherit the donor body's gestures and movements, as well as most of his or her diseases. ${ }^{7}$

Bioethicists have posed other questions as well. Some are relatively academic: if the recipient of the body transplant was married prior to the operation, would their spouse be breaking the marriage contract by having sex with them ? $^{8}$ Other observations are more practical: if the hybrid person subsequently has children, they would genetically be the children of the body donor. If the body donor previously had children, or other prior civil or contractual obligations or criminal liabilities, new legal definitions would need to be worked out to ascertain that the hybrid would not be accountable for them.

An added concern is posed by the historical lack of transparency regarding the sourcing of organ donors - and, by implication, donor cadavers in China, the country that has hosted, funded, and authorised Canavero and Ren's research toward the world's first head transplant. China has a history of harvesting organs from condemned prisoners. Considerable reforms have been achieved since the state rolled out a nationwide voluntary organ donation system in 2013, and officially prohibited the use of organs from executed criminals in 2015. Noting that transplant patients need to take immunosuppressant drugs for life, a Washington Post investigation concluded that China's consumption 'of immunosuppressants is roughly in line with the number of transplants of voluntarily donated organs it says it carries out'. ${ }^{9}$ Allegations of prisoners continuing to be eligible for 'voluntary' organ donation persist. But former deputy health minister Huang Jiefu 黄洁夫 — an Australian-trained renal transplant surgeon and honorary professor at Sydney University's medical school from 20082014, now in charge of the national commission overseeing the overhaul of the country's organ donation system insists that there is zero tolerance for such practices now, admitting that they may still continue to be carried out illegally here and there. ${ }^{10}$ 
It is clear that Canavero and Ren could not carry out their research in Europe or the United States; the project would simply never get past a bioethics committee. They have responded to the criticism of their venture in $A J O B$ Neuroscience, pointing out that their project is merely a final point in the trajectory of transplant surgery. While transplant surgeons Joseph Murray and Christiaan Barnard, who performed the world's first kidney and heart transplants in 1954 and 1967 respectively, were subject to similar onslaughts of ethical and scientific criticism, the procedures pioneered by them are fairly standard today. Canavero and Ren further note the historically and culturally situated nature of Judaeo-Christian bioethics, claiming that there is a 'cognitive riff' between Western ethics and 'pragmatic' Chinese philosophy, or even ' $[\mathrm{t}] \mathrm{he}$ Chinese mind, which is problem-solving and speculation (and schoolyard squabble) averse'. ${ }^{11}$ In Canavero's words: 'Western bioethicists needed to stop patronising the world'. ${ }^{12}$ Adding that their 'experimentation has been copious' but that they have chosen to only make it available to relevant Chinese authorities, instead of sharing it with the international scientific communi- ty: 'Since the West stubbornly refuses to look at the facts, there is no point in sharing innovative technology with other foreign parties'. ${ }^{13}$

Ren and Canavero's portrayal of China as a country free of the shackles of ethical traditions that would hamper scientific enquiry betrays their ignorance. For one, there is no lack of material for constructing arguments against human head transplants in China's philosophical and religious traditions, and there are Chinese ethicists who have applied themselves to that task. ${ }^{14}$ Moreover, the ethical guidelines that are in place in China, do not - at least on paper - differ substantially from international conventions. ${ }^{15}$ Indeed, Ren and Canavero's project has also met with scepticism and objections from within China, voiced by medical ethicists at Peking University, and even Huang Jiefu himself. ${ }^{16}$

And yet, it is undeniable that in its bid for global leadership in biomedical research, China has kept crossing contentious lines: on 24 January 2018, the Nonhuman Primate Research Facility of the Chinese Academy of Social Sciences Institute of Neurosciences, Shanghai, reported having cloned two macaque monkeys, using the same technique that produced 


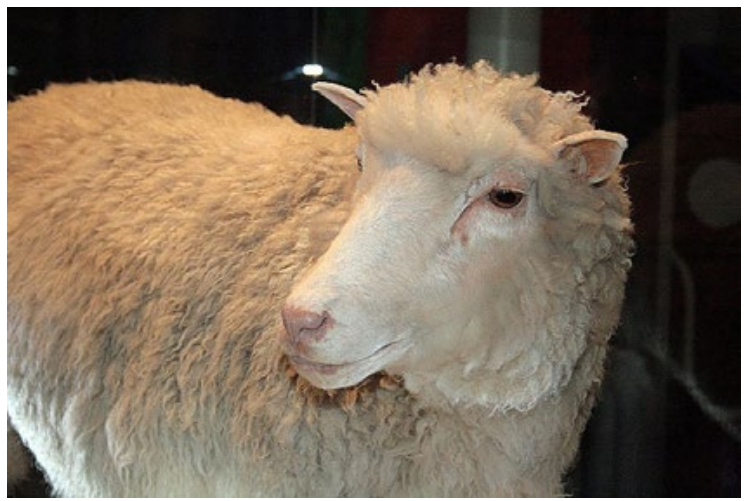

Dolly the sheep. These monkeys are the first primates ever to be cloned, and signify a breakthrough in a technical barrier that brings humanity yet one step closer to the possibility of human clones. ${ }^{17}$ On 26 November 2018, American-trained chinese scientist He Jiankui 贺建奎 shocked the world by revealing that he was responsible for the birth of the world's first geneedited babies in Shenzhen - twin girls whose DNA he modified with a tool called CRISPR-Cas9 in order to make them resistant to HIV. ${ }^{18}$ Shortly after, on 23 January 2019, the Institute of Neuroscience of the Chinese Academy of Social Sciences, Shanghai reported the birth of five CRISPR gene-edited macaque monkey clones - an ethical minefield combining the cloning of nonhuman primates with the application of CRISPR technology, creating a cohort of genetically altered monkeys with identical DNA to be used in laboratory research.

Considered dangerous for humans, CRISPR-Cas9 is also the tool that allows editing out the genes of pigs that trigger immune response in humans and to inactivate porcine endogenous viruses (PERVs) in the pig genome. These edits pave the way for so-called xenotransplants - that is, pig organs transplanted into human organisms. On 10 August 2017, scientists working for the Cambridge biotech start-up eGenesis (cofounded in 2015 by George Church - Harvard Medical School Professor and Core Faculty Member of Harvard's Wyss Institute for Biologically Inspired Engineering - and his former doctoral student Yang Luhan 杨路䒱) reported the birth of 37 PERVfree baby pigs in China. They belong to 
a breed of miniature pigs with organs just the right size for transplanting into human recipients. ${ }^{19}$ China is already home to the world's biggest pig cloning farms, which are associated with a national xenotransplantation project involving ten research units and is funded by the central government. According to an informant to the South China Morning Post who wishes to remain anonymous, China is producing about 1,000 cloned piglets a year, with trials of pig organ implantation into primates ongoing. Xenotransplant scientists are presently waiting for the green light to commence clinical trials on transplanting pig organs into humans. ${ }^{20}$

In view of all this, it appears that Canavero and Ren were not far off the mark in contending that ' $[\mathrm{t}] \mathrm{he}$ People's Republic of China (PRC) is committed to achieving superpower status on all levels, including biomedical research. Chinese scientists are already leading in the field of gene editing, and the PRC is set to overtake the US as the foremost transplant country in the world by 2020; it also plans the first pig organ transplants by that date'. ${ }^{21}$ What we are seeing in China right now is the implementation of a global science, an early intimation of the challenges and possibilities for the future of humanity writ large. Bioethicists and medical doctors in China and the West would do well to collaborate in developing a shared ethical framework to set the parameters in which future experiments can take place. 
This text is taken from China Story Yearbook 2018: Power, edited by Jane Golley, Linda Jaivin, Paul J. Farrelly and Sharon Strange, published 2019 by ANU Press, The Australian National University, Canberra, Australia.

doi.org/10.22459/CSY.2019.09A 